\title{
АНАТОМИЧЕСКОЕ ОБОСНОВАНИЕ ПЛАСТИКИ СОСКОВО-АРЕОЛЯРНОГО КОМПЛЕКСА
}

Горбань Мария Евгеньевна Аспирант

Белова Елизавета Александровна Томаев Юрий Олегович

Студенты

Научный руководитель: Горбунов Николай Станиславович д.м.н., профессор

ФГБОУ ВО "Красноярский государственный медицинский университет имени профессора В.Ф. Войно-Ясенецкого"

Аннотация: Анализ работ по изучению тактильной чувствительности сосково-ареолярного комплекса и медиальной поверхности плеча показал, что во всех исследуемых квадрантах груди и в области медиальной поверхности плеча чувствительность положительная. Медиальный кожный нерв плеча обеспечивает чувствительную иннервацию кожи медиальной поверхности плеча. Нерв может быть использован при восстановлении чувствительности сосково-ареолярного комплекса после радикальной мастэктомии. Но для использования нейросенсорного кожного лоскута для замещения дефектов участков кожи медиальный кожный нерв плеча изучен недостаточно.

Ключевые слова: топографическая анатомия, рак груди, мастэктомия, трансплантация нерва, антомия, сосково-ареоларный комплекс, пластика.

\section{ANATOMICAL SUBSTANTIATION OF PLASTIC SURGERY OF THE NIPPLE-AREOLAR COMPLEX}

\author{
Gorban Maria Evgenievna \\ Belova Elizaveta Alexandrovna \\ Tomaev Yuri Olegovich \\ Scientific adviser: Gorbunov Nikolay Stanislavovich
}

\begin{abstract}
The analysis of works on the study of tactile sensitivity of the nipple-areolar complex and the medial surface of the shoulder showed that in all the studied quadrants of the chest and in the medial surface of the shoulder sensitivity is


positive. The medial cutaneous nerve of the shoulder provides sensitive innervation of the skin of the medial surface of the shoulder. The nerve can be used to restore the sensitivity of the nipple-areolar complex after radical mastectomy. But the medial cutaneous nerve of the shoulder has not been studied enough to use a sensorineural skin flap to replace skin defects.

Key words: topographic anatomy, breast cancer, mastectomy, nerve transplantation, anatomy, nipple-areolar complex, plastic surgery.

Актуальность.

Рак молочной железы - актуальная проблема современной медицины, который занимает первое место по заболеваемости среди женщин и имеет высокий темп прироста. В мире ежегодно диагностируется 1,3 миллиона новых случаев, треть от которых заканчиваются летальный исходом, с каждым годом прирост заболеваемости увеличивается на 30 \% [1, с. 102].

Одним из методов лечения рака молочной железы является радикальная мастэктомия. Но после радикальной операции встаёт вопрос о реконструкции молочной железы с восстановлением чувствительности сосковоареолярного комплекса.

\section{Цели исследования -}

1. Анатомическое обоснование пластики сосково-ареолярного комплекса в связис особенностями топографического расположения медиального кожного нерва плеча.

2. Рассмотреть пластику сосково-ареолярного комплекса с точки зрения самостоятельной операции по реконструкции чувствительности зон молочной железы.

3. Проанализировать научную литературу для создания понимания о вариантах формирования медиального кожного нерва плеча [2, с. 598], $[3$, c. 72$]$.

4. Обозначить варианты топографического расположения медиального кожного нерва плеча.

5. Анатомически обосновать пластику сосково-ареолярного комплекса.

Материалы и методы.

Материалами нашего исследования являются 46 трупов мужчин и женщин в возрасте 36-90 лет проживавших в г. Красноярске. Для изучения нерва были выделены следующие критерии включения в исследование: не 340 
подвергшиеся патологоанатомическому вскрытию трупы мужчин и женщин 3690 лет без травм головы, шеи, верхней конечности.

В нашей работе мы использовали следующие методы: антропометрический, статистический, послойное анатомическое препарирование [2, с.720].

Результаты.

В ходе исследования материалов обнаружены следующие топографические варианты формирования медиального кожного нерва плеча.

В 43\% случаев медиальный кожный нерв плеча формируется из медиального пучка плечевого сплетения.

В 10\% случаев нерв формируется из медиального пучка плечевого сплетения и первого межреберного нерва.

В 2\% случаев нерв формируется из первого и второго межреберного нерва.

В 10\% случаев медиальный кожный нерв плеча отсутствует.

В 29\% случаев нерв формируется из медиального пучка плечевого сплетения и второго межреберного нерва.

В 2\% случаев нерв формируется только из первого межреберного нерва.

В 4\% случаев нерв формируется только из второго межреберного нерва.

В ходе анализа полученных данных были определены границы вариантных значений:

Длина нерва:

- минимальная $=13,5$ см

- максимальная $=30 \mathrm{~cm}$

Расстояние от нижнего края середины ключицы до отхождения нерва: минимальное $=1 \mathrm{~cm}$

- максимальное $=6 \mathrm{~cm}$

Выводы.

Медиальный кожный нерв плеча встречается в 90\% случаев, а в 10\% отсутствует.

Иннервация кожи медиальной поверхности плеча в последнем случае осуществляется веточками, отходящими от лучевого, локтевого, медиального кожного нерва предплечья и межреберных нервов [4, с.93].

Выявлено 7 вариантов формирования медиального кожного нерва плеча. 
Измерение длины медиального кожного нерва плеча позволяет подтвердить логичность его применения для пластики сосково-ареолярного комплекса

Необходим поиск внешних придатков наличия медиального кожного нерва плеча и вариантного формирования для предоперационного выбора методики формирования чувствительности реконструируемой молочной железы.

\section{Список литературы}

1. Петерсон С. Б., Онкология [Электронный ресурс] / под общей ред. С. Б. Петерсона - М. : ГЭОТАР-Медиа, 2014. - 288 с. - ISBN 978-5-9704-2532-9

2. Привес М. Г., Лысенков Н. К., Бушкович В. И. Анатомия человека.11-е изд., испр. и доп.-СПб.: Гиппократ, 2001.

3. Островерхов Г.Е. Оперативная хирургия и топографическая анатомия [Текст]: учеб. для мед. вузов / Г. Е. Островерхов, Ю. М. Бомаш, Д. Н. Лубоцкий. - 5-е изд., испр. - М.: МИА, 2013. - 736 с.

4. Сергиенко В. И. Топографическая анатомия и оперативная хирургия. В 2 т. [Текст]: учеб. для вузов / В. И. Сергиенко, Э. А. Петросян, И. В. Фаучи; под ред. Ю.М. Лопухина. - 3-е изд., испр. - М.: ГЭОТАР- Медиа, 2007 -.т.1. - 832 с.

5. Топографическая анатомия и оперативная хирургия: учебник. В 2-х томах. / Под ред. И. И. Кагана, И. Д. Кирпатовского. 2012. - 512 с.

(C) М.Е. Горбань, Е.А. Белова, Ю.О. Томаев, 2022 